\title{
XLIV. Microscopic examination of some of the principal tissues of the animal frame, as observed in the tongue of the living Frog, Toad, \&c.
}

\section{Augustus Waller M.D.}

To cite this article: Augustus Waller M.D. (1846) XLIV. Microscopic examination of some of the principal tissues of the animal frame, as observed in the tongue of the living Frog, Toad, \&c. , Philosophical Magazine Series 3, 29:194, 271-287, DOI: 10.1080/14786444608645504

To link to this article: http://dx.doi.org/10.1080/14786444608645504

曲 Published online: 30 Apr 2009.

Submit your article to this journal $[\pi$

Џll Article views: 5

Q View related articles $\llbracket$ 
carbonated alkalies, carbonic acid being disengaged on boiling, but it is insoluble in lime and baryta water. The solution in ammonia gives with chloride of calcium and chloride of barium flocculent precipitates, consisting of roccellate of lime and baryta. A solution of roccellic acid in alcohol is precipitated by an alcoholic solution of acetate of lead, but not by a solution of nitrate of silver. A solution of it in ammonia gives with nitrate of silver a white gelatinous precipitate, which becomes brown when the fluid is boiled, but is not completely reduced. An alcoholic solution of roccellic acid does not reduce chloride of gold on boiling.

On being ignited with oxide of copper-

I. $0.42100 \mathrm{grm}$. gave 1.0200 carbonic acid and 0.4025 water. II. $0.2815 \mathrm{grm}$. gave 0.6795 carbonic acid and 0.2720 water.

From these numbers the following composition may be deduced:-

\begin{tabular}{|c|c|c|c|c|c|c|}
\hline & & & 1800.0 & $\begin{array}{c}\text { Calculated. } \\
66^{\circ} 97\end{array}$ & $\begin{array}{c}\text { I. } \\
66.07\end{array}$ & II. \\
\hline 23 & ... & Hyd & 28 & $10 \cdot 69$ & $10 \cdot 62$ & 10.73 \\
\hline 6 & $\ldots$ & Oxygen. & $600 \cdot 0$ & $22 \cdot 34$ & $23 \cdot 31$ & $23 \cdot 44$ \\
\hline & & & $\overline{2687 \cdot 5}$ & $\overline{100^{\circ} 00}$ & $\overline{100 \cdot 00}$ & $100^{\circ}$ \\
\hline
\end{tabular}

The lead salt was prepared by dissolving the acid in a small quantity of ammonia and precipitating with acetate of lead.

I. 0.4475 grm. gave 0.5530 carbonic acid and 0.2070 water. 0.3405 grm. gave 0.0705 lead and 0.0990 oxide of lead.

II. 0.4360 grm. gave 0.5490 carbonic acid and 0.2025 water. 0.2860 grm. gave 0.0730 lead and 0.0675 oxide of lead.

These numbers correspond to the following composition:-

\begin{tabular}{|c|c|c|c|c|c|c|}
\hline \multirow{2}{*}{\multicolumn{4}{|c|}{ o4 enuive Carhon }} & Calculated. & 1. & II. \\
\hline & & Carbon & 1800 & $33 \cdot 55$ & $33 \cdot 70$ & $34 \cdot 34$ \\
\hline 22 & ... & Hydrogen & 275 & $5 \cdot 12$ & $5 \cdot 13$ & $5 \cdot 16$ \\
\hline 5 & $\ldots$ & Oxygen . & 500 & $9 \cdot 34$ & $9 \cdot 81$ & $9 \cdot 42$ \\
\hline 2 & $\ldots$ & Oxide of lead & 2789 & $51 \cdot 99$ & $51 \cdot 36$ & $51 \cdot 08$ \\
\hline & & & $\overline{5364}$ & $100 \cdot 00$ & $100 \cdot 00$ & $100 \cdot 00$ \\
\hline
\end{tabular}

This salt is therefore basic. I have been prevented by want of material from examining the other salts of the acid.

XLIV. Microscopic Examination of some of the principal Tissues of the Animal Frame, as observed in the Tongue of the living Frog, Toad, \&c. By Augustus Waller, M.D.* [With a Plate.]

7 'HE peculiar structure and disposition of the tongue of the frog affords great facilities for its examination under the * Communicated by the Author. 
strongest magnifying powers we possess. It is inserted by the base to the concavity of the lower jaw-bone, and the point hangs down the pharynx perfectly free from any adherence. It presents great resemblance to the uvula in the human subject in size, shape and colour, which also has its lower extremity free and hanging down the pharynx. The peculiar habits of the frog completely explain the apparently anomalous disposition of the tongue; as, independently of its being an organ of taste, it likewise serves the purpose of one of prehension for supplying the animal with food. As is well known to naturalists, it subsists on flies and small insects which it seizes in their flight. On these occasions it darts its head forward, at the same time projecting the tongue out of the mouth, the upper surface of which being covered with a slimy exudation, comes in contact with the insect, folds round it and draws it back into the mouth. In this little manœuvre the tongue may be considered as performing a movement of rotation of $180^{\circ}$ round the lower jaw-bone, so that the surface which is uppermost in the mouth becomes lowermost when in contact with the object. This fact must be borne in mind when the tongue is examined under the microscope, for then likewise the inferior surface is uppermost, and the superior or papillary surface below.

I take this opportunity of stating my claim of priority with regard to this experiment, as a very erroneous impression might be created by M. Donné's statement in his Cours de Microscopie. It was first performed by the in Paris in 1839. 'The idea occurred to me while making some dissections of the frog for the purpose of comparative anatomy; and at first $I$ merely applied it to test M. Dumas's well-known theory of muscular contraction. Subsequently I repeated it in the presence of several of my friends, among whom I may particularly mention $\mathrm{Mr}$. Thomas Cooper. Success in this point encouraged me to attempt to observe the circulation in the human subject; and as the prepuce in some cases is nearly semi-transparent, I fixed upon that membrane as the subject of experiment. For an obvious reason I was desirous of not making these experiments alone, and obtained the assistance of $\mathrm{M}$. Donné. After a few attempts we finally abandoned the subject; although I am still of opinion that they would be successful if tried under favourable circumstances. While engaged in this pursuit I stated to him that I had already discovered a living membrane, containing muscles and glands in its natural state, without the aid of the scalpel. From the interest with which I found this observation received by him, I was induced to repeat the experiment as described, and we determined to 
prosecute it in common. My surprise therefore was great, when a few days after I was informed (without any intimation from M. Donné) that he had communicated the experiment to the Société Philomatique. At the next meeting of the Society I attended, and found that in the proces verbal of the preceding meeting, in giving an account of the experiment, M. Donné had omitted to mention my name and co-operation. I seized the opportunity to rectify this mistake, and to state the arrangement that I had made with M. Donné, and to disclaim any precedence on his part. I have only to add, that these statements were made before a very full meeting of the members, that M. Donné was present, and that they were received by him without contradiction. I should not have deemed it necessary to enter into these details if $I$ had not seen at page 108 of his Cours de Microscopie an account of these observations almost literally the same as inserted in the minutes of the Sociéte Philomatique, with the following slight comment:- "Voici comment se prépare cette belle expérience dont l'idée première $m$ 'a été donné par un élève étranger, qui suivait mes cours, M. Waller."

To prepare the animal for the experinent, it must be rolled up in a strip of linen, leaving the head and the extremities of the legs uncovered. Arranged in this kind of swaddling bandage with a little care, it is incapacitated from making any violent movement, which is indispensable for the success of the experiment, while at the same time it is perfectly able to breathe. We must next provide a slip of sheet-cork rather longer than the frog: at one extremity a circular piece about

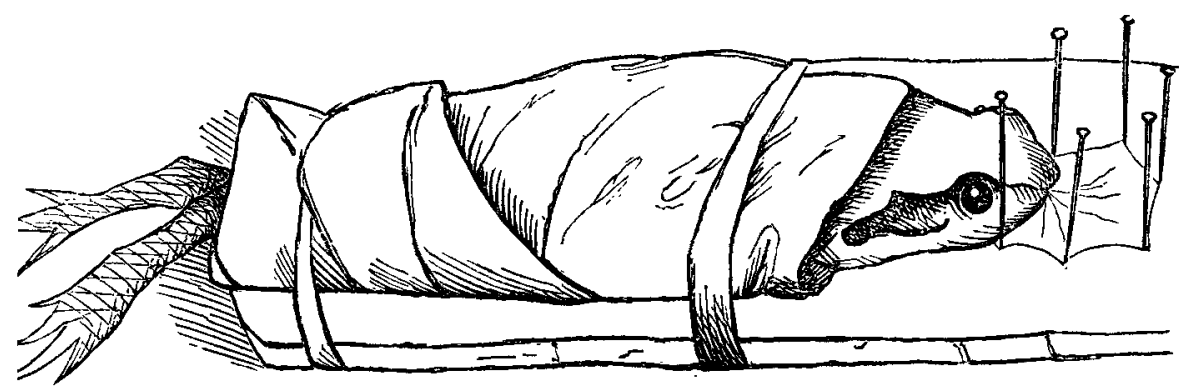

the size of a shilling is to be cut out, so as to form an opening to allow of the passage of light when the tongue has been stretched over the opening. The frog is now to be placed on the slip of cork, where it may be secured by a few turns 


\section{Dr. Waller on some Tissues of the Animal Frame,}

of string, or by a couple of elastic bands, which I have found more convenient. The animal's tongue may now be easily discovered as described, and drawn out of the mouth with a pair of tweezers. It will now be perceived (as I first observed while dissecting one of these animals) that this organ possesses an extraordinary degree of elasticity, and that with care it may be extended in all directions until it is so attenu. ated as to become nearly transparent. A few pins will enable us to fix it over the opening made in the cork, where we can examine it at our leisure.

When the tongue is first extracted from the mouth it is observed to be extremely pale, and the only vessels visible are two veins with accompanying arteries, corresponding to the lingual arteries in man, which, after ascending the throat in a parallel direction, penetrate into the tongue, where they are chiefly distributed at its inferior surface. In the substance of the tongue they may be described in general terms as proceeding by their main trunks towards the two tnbercles, which are found at its anterior extremity, and communicating in their course by frequent anastomoses. After several minutes' exposure they become more apparent from the general vascular distention that takes place, and we observe the same phænomena as when the conjunctiva is exposed to the contact of some foreign substance. Thus the vessels become more distended and apparently increased in number, at the same time they appear to terminate in the tissue of the organ, like the minute fibres of roots.

This vascular engorgement appears to arise in the first instance entirely from the vital irritability of the organ, as it is seen to commence as soon as the tongue is seized by the tweezers, even before it is extracted from the mouth. After its preparation this injection is further increased by the impedi. ments which exist to free respiration and muscular action. The peculiar manner in which this animal, devoid of ribs, breathes, is will known. The number of respirations in a minute depends much upon the external temperature, and varies from four to thirty. The pulsations of the heart in the same period are about sixty, which we may ascertain by observing the skin over the heart as it rises at each contraction. Acquaintance with these facts will be found useful in the subsequent inquiry. Nervous trunks, in colour of a shining white, are found accompanying the vessels, and are best seen when the extended tongue is viewed between the light.

On the upper or papillary surface the eye detects minute elevations above the rest of the membranes, which very much resemble the granulations often existing on the inner surface 
of the eyelids : when this surface is covered with ink, these minute elevations become still more apparent.

Microscopic Examination. - It will be found advisable to commence this examinatiom by means of the simple microscope, as it offers us at one view the principal phænomena to be observed; and for this purpose a lens of nioderate power will suffice.

The blood-vessels, which to the naked eye appeared to terminate so abruptly, are seen to be continuous canals carrying blood in opposite directions. In the arteries the direction of the blood appear's to be centripetal, from the inversion caused by the instrument, and the globules are pale. The veins are more voluminous than the arteries, and contain blood much darker, moving more slowly.

The minute elevations on the upper surface are seen to be of two kinds; one like small transparent grapes, within which there is a very active circulation; and the other of a conical shape, adherent at the base and destitute of internal circulation. The first are minute glands, the latter are the papillæ in which probably resides the power of taste.

The nerves are recognised by their wavy' direction, their dark outlines by transmitted light, and their whiteness when viewed by reflexion.

Epithelium.-The scales of epithelium form a layer which covers every part of the upper surface of the tongue, and are the first parts which offer themselves to the microscopic observer. With a strong magnifying power they present a most interesting appearance, like a mosaic pavement, or a complete scaly armour covering the papillæ and the glands, descending into the interior of the latter, and into all the deeper inequalities that are found on the surface of the tongue. They may be seen equally well whether the animal is alive or dead; but if alive, it is preferable to choose one whose tongue is pale, and does not become rapidly injected when extracted from the mouth. With a little care of this kind, which applies equally to most of the following observations, it will be found easy to submit this organ to the strongest magnifying powers. The scales are much smaller than those found in the same region in man, or those which constitute the epidermis. In size they average from $\frac{1}{500}$ th to $\frac{1}{370} \overline{0}^{\text {th }}$ of an inch. In form they are not perfectly regular, but generally rhombic or hexagonal, and sometimes of an elongated prismatic shape. They are mostly placed side by side in close juxtaposition, frequently overlapping each other. With a magnifying power of 600 diameters these bodies present on their surface an irregular punctuated appearance, such as might arise from the exist- 
ence of small filaments projecting upwards in a vertical direction, and which are probably the ciliary filaments with which they are studded.

The flattened appearance of the epithelial scales, I believe, is owing to the manner in which the light is transmitted through the membrane, which gives a view of their horizontal section, but conveys no idea of their projection upwards. I am led to this conclusion from the appearance of the papilla and glands, which project upwards into the mucous membrane, and are found to present at their borders several projections, such as we should expect from small bodies shaped like those figured by Henle, as existing on the inner side of the cheek in man. In Plate I. figs. 1 and 2, may be seen these toothed projections corresponding in size to the scales, which corroborates the view of regarding each of them as forming a small conical projection above the membranes. The scales on the under surface are much smaller and more indistinct, but are the same in other respects.

Cilia and ciliary movements.-These may be seen with great facility at the upper surface, when a sharp border of the tongue is examined under strong magnifying power. For this purpose a portion of the tongue is to be placed between two slips of glass with a little water: the foreign particles in suspension will then show by their agitation the existence of the ciliary motion, which will be seen at the borders of the membrane. There will be perceived, under favourable circumstances, minute projections or filaments; but more fiequently there will be seen merely a kind of flittering movement, without the cilia which give rise to it being distinguished separately. These cilia were not included in the communication to the Sociéte Philomatique, and their detection is due to M. Donné at a subsequent period.

Tongue of the Toad.-It is covered with more irregular epithelia, generally not so large as those of the Frog; in other respects they are much alike.

Tongue of the Lizard.-It is very remarkable for the thick and horny papilla with which it is covered. These are all protected by a covering which is much like the epidermis. The layer of papillæ presents no appearance of circulation on the surface, and is too opake to allow any passage of light; but when the tongue is retained out of the mouth 1 have often observed the circulation at the borders; and the globules of blood are sufficiently voluminous to be easily seen by the simple microscope.

Papille, Glands, \&c.-On the frog's tongue, immediately beneath the layer of epithelian scales, are seen various small 


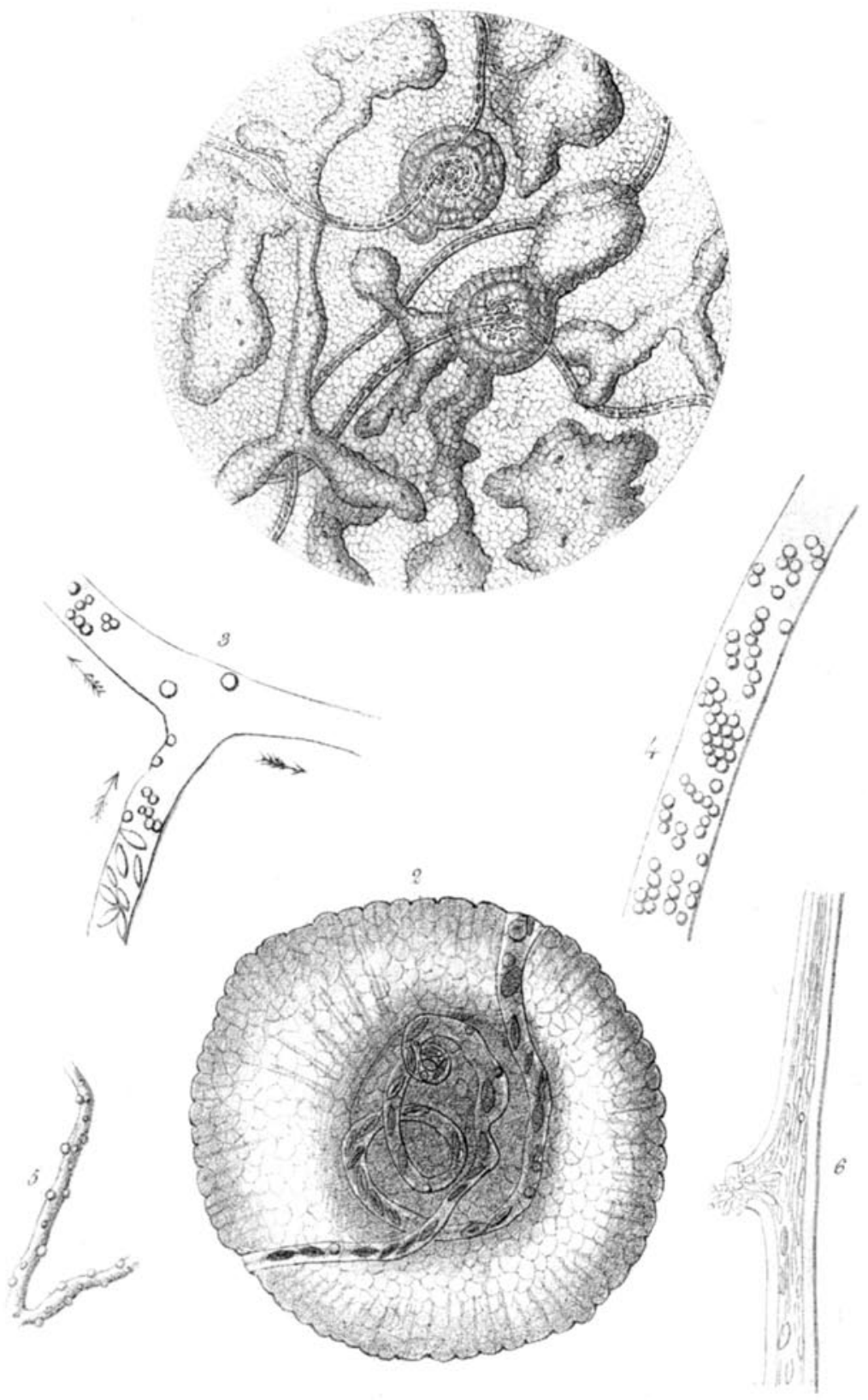


Dodies of irregular curved outlines, which may be considered as the second anatomical stratum of the tongue; these consist of papillæ, small glands and mucous follicles.

The papillæ are small bodies of a cylindrical, conical or club-like shape, connected at the base so as to be continuous throughout. In thickness or breadth they vary between about

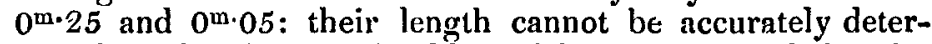
mined, as they have no fixed line of demarcation at their point of insertion on the mucous membrane. No appearance of any circulation is found in any of these papillæ: the blood-vessels run by them, sometimes forming vascular loops, but are rarely seen to penetrate through them; and even in those cases the vessel is frequently external to the papilla, which is sufficiently transparent to allow the blood-vessel to be seen throngh it. In inspecting the surface of the tongue, especially when the high powers are used, a mistake may be easily made, against which I wish to guard those who may repeat these experiments: it consists in the appearance of numerous curved lines ruoning in every direction, perfectly black, and apparently very defined. These lines have been supposed to be loops of nervous fibres; and M. Donné appears still to labour under that erroneous idea, when at page 116, Cours de Microscopie, he says, "d'autres taches grises se remarquent. ..... Je les crois formées par des houppes nerveuses." These lines are nothing more than the outlines of the papilla of fig. 1, seen not exactly at the right focus.

From the nature of their structure and functions we should expect to find some nervous filaments in the interior of the papillæ; and probably such do exist, though I have not yet been able to detect them. The nervous fibres, which are found below this layer, will be examined hereafter. 'They never present any opening; the dark points sometimes seen at their apex belong to some central spots of the epithelial scales, with which they are covered as with a glove; nor do they ever appear flaccid or empty.

Glands *.-The glands of the frog's tongue differ from the papillæ by the very active circulation which they present in their interior. They are always of a globular shape, more prominent and larger on the suiface than the papilla, being generally about the $5^{\frac{1}{0}}$ th of an inch. The circulation in these small glands is very interesting to witness, as we can trace the progress of the particles of the blood as they enter into the centre of the gland, and follow them in all their movements, until they make their exit in the capillary vessel which

* These will be shown hereafter to resemble the fungiform papillæ in the human subject. 
conveys them to the venous branches. The movement of the blood in the gland may be compared to that in small whirlpools; and at first it does appear as if the blood were animated by a circular movement, in a small spherical cavity at the centre of the gland, without its being contained in any capillary vessel. This appearance however is illusory, and created by the rapid motion of the blood in a coil of transparent vessels, which are twisted up on this spot into a spherical shape. The limits of this vascular nucleus are well-defined, and are generally found to occupy half the diameter of the gland, or about $\frac{1}{1000}$ th of an inch. When engorged with blood it is easy to perceive the coils of capillaries; and their continuity may be traced to the ends, which, as in fig. 2, bring the blood and convey it away. The two extremities are generally found at opposite sides of the gland, as in fig. 2. When perfectly empty it is almost impossible to detect these coils; but there may be seen, however, a distinct outline, which probably consists of the membrane, upon which is secreted the fluid contained in the external transparent area. The rate at which the blood moves in these coils is constantly varying; sometimes it is so quick that the globules are only perceptible by a flitting appearance, and in a few moments afterwards it becomes stationary. In favourable circumstances, when the red globules are scanty and the circulation slow, one of them will arrive in the gland, and may be followed in the various gyrations it performs; at one moment ascending in the superficial curves, at other times descending and passing in to others placed deeper. Some idea may be formed in this way of the considerable extent of the capillary convolutions. The blood does not circulate with equal rapidity in different glands at the same moment; for there may be seen at the same time some in which the blood is stationary, and others in which it moves with extreme quickness. The external area, which, divested of the epithelial scales, would be transparent, comprises the other half of the diameter of the gland: within this the contents are perfectly motionless. In some there appears a radiated structure distinct from the epithelial covering, constituting separate compartments or cells in its interior: they contain a fluid substance void of granules or other particles perceptible by the microscope.

In general no opening is to be perceived on the surface of the gland for the passage of the fluid after it has been secreted; but in favourable instances a small opening with scales of epithelium around its borders can be seen, descending apparently into the cavity of the gland. Although it is difficult to demonstrate the existence of an aperture or duct, it is easy to ascer- 
tain that the secretion which lubrifies the surface of the tongue is very abundant over these bodies, and that it appears to arise from them. On examining the fluid, it was found to be a thick mucus, withont any of the globules commonly known to characterize it.

The tongue of the toad presents likewise numerous papilla and glands similar to those of the frog. In addition, numerous depressions in the mucous membrane are frequently seen, which are of the same nature as the mucous follicles or crypts in man. Around them and on their exterior we find a very abundant network of capillaries.

Vascular System and Circulation.-Having examined the glands, which may be considered as appendages of the vascular system, I now proceed to describe other phænomena of the same system, as observed in its general distribution throughout the tongue. The blood, we are aware, consists of a transparent fluid holding in suspension numerous particles, most of which are red and of a flattened shape, while a few others are colourless, and spherical in form. 'The various movements and appearances presented by these particles in their circuit from the arteries to the veins, constitute the principal phænomena to be observed by the microscope. The tongue offers great facility for observing the two opposite currents in the veins and arteries, as they run together side by side for a considerable distance in that organ.

I have already mentioned the rapid injection of the tongue as soon as it is subjected to the experiment, from the irritation caused by extracting it from the mouth. The degree of rapidity with which this takes place varies in different subjects, even when they are selected as similar as possible with regard to age, size, \&c. These varieties are to be attributed to certain constitutional differences or idiosyncrasies, such as we find in human beings, and which are found to exist in a minor degree throughout the animal kingdom, and are inseparable from animal life. While preparing the tongue, we find likewise some of these constitutional peculiarities; for in some subjects it may be expanded without the least laceration, while in others it is extremely liable to tear with the slightest force used. In proportion as we penetrate more closely into the structure of this organ, we find numerous peculiarities of structure referable to the same cause; but particularly when examining the changes which occur in the vascular system, these evidences of constitutional peculiarities are more apparent. As this point is intimately connected with the vital functions, and may lead us to a better acquaintance with the laws by which they are governed, it is unnecessary to point out the interest with which it deserves to be examined. 
We may estimate in some measure the changes which occur in the tongue when under the influence of irritation, by examining it in an animal recently dead, and without its having been subjected to any previous irritation. The capillaries visible are then found to be comparatively very few in number, and less engorged with blood; but as the blood in this case is perfectly motionless, it is still better to prepare a subject as speedily as possible, when the increase of the number of capillaries may be easily watched. Vessels which before were invisible, are then revealed by the passage of a few particles of blood in a certain defined direction, gradually becoming more distinct. I have never been able to satisfy myself on these occasions of the formation of any new channels for the blood; on the contrary, they have always appeared to me to be perfectly defined and distinct from the first moment of their appearance. The most remarkable changes to be observed in the tongue are the following:-

1. Engorgement of the Capillaries.-The capillaries are rapidly injected with blood, which becomes stagnant. Circulation is only seen at a few points. The arteries still continue to pour their contents, while the current in the vein becomes more and more languid, until at length it ceases entirely. The vessels appear to contain a red substance, in which we cannot easily detect the separate red particles. The lymph-globules are sometimes seen distinct within the vessels, but they are not generally very abundant : whenever a muscular movement is made, it is found to give rise to a brisk movement of the blood, which continues several instants afterwards.

2. An increased action in the Capillaries.-The stagnation in the capillaries is very slowly produced, for many hours we may witness the admirable sight of these vascular currents moving rapidly in all directions. At one place are the discs, passing through canals sufficiently large to allow several to pass at a time: by tracing this canal towards its extremity we find its calibre gradually diminish, until at length the discs or spherules can only pass one at a time. In these vessels may be frequently seen, as it has been described, the state of oscillation of the fluid column, the temporary stagnation of some loop, which is afterwards succeeded by the globules passing with great rapidity, while the adjoining loops in their turn become inactive; at other times the direction of the current in the loop takes an opposite course, which may continue as long as the examination lasts.

The most efficient cause in producing these changes in the capillary circulation is, without doubt, muscular contraction; for whenever that occurs, a state of great activity is produced 
in the circulation for several moments, and the inertia of several of the fluid columns is overcome. In recognising the influence of muscular action on the circulation, we must not forget that this is merely auxiliary to the great action of the heart, and that it only occurs at irregular intervals.

The action of the heart itself may be traced into the minutest capillaries, and even sometimes to the large venous trunks, by the periodical acceleration of the vascular columII. I have already described the manner to detect the pulsations of the heart of the frog: I found the average number to be sixty-four in a minute. By counting the acceleration of blood in the artery, these two are found to correspond with great precision. In the same way, by accurately noting the time, we may in most cases observe a similar acceleration in the minute capillaries, and even in the veins. Müller has already noticed an oscillating movement in the capillaries, when the animal is in a state of great exhaustion; but in my experiments $I$ have been able to detect it from the commencement without any impairment of the vital powers. In these instances the number of accelerated movements in a minute is about thirtyeight, and they are synchronous with the contractions of the heart: in the accompanying vein at the same time I have also perceived a slight oscillating movement of the blood. By a little practice the synchronous action of the capillaries and the heari will scarcely ever fail to be perceived.

3. Corpusculation of Capillaries.-The peculiar manner in which the lymph-globules, or corpuscles, conduct themselves in the capillaries, when in an organ in a state of irritation, has of late engaged much attention. The experiments of $\mathrm{Mr}$. W. Addison of Malvern, have greatly contributed to show these important functions in inflammation. In the tongue of the frog and toad they may be frequently seen circulating with the red particles in the vessels, down to the minutest capillaries. As it has already been pointed out, these spherules are generally found, when they come in contact with the parietes of the vessels, to retain their adherence with greater force than is manifested by the red particles in the like circumstances; as in fig. 3, where the current was observed to continue for many minutes without cisplacing the globules near the sides of the vessel. Thus we frequently see a lymph-globule remain in the same place, notwithstanding the current of red particles sweeping and pushing by it. From its globular form we should have expected, $\grave{a}$ priori, that the contrary would have been the case. The appearance in the larger vessels of these spherules, adherent to their inner surface, has been very aptly compared Phil. Mag. S. 3. Vol. 29. No. 194. Oct. 1846. 
to so many pebbles or marbles over which a stream runs without disturbing them. Another arrangement of them in the capillaries is shown in fig. 4 , where the vessel is occupied solely by these spherules. 'This is only to be found near the borders of the tongue, where we may suppose that the greatest irritation exists. The spherules are there found to be quite motionless, and not a single red particle can be detected at any point of the vessel, which, in the case in question, was followed for a considerable length. The corpuscles, which are transparent, are occasionally seen to be granulated. It appears to be very doubtful whether this corpusculation (if I may be allowed the expression) is an invariable accompaniment of all cases of irritative congestion or inflammatory action, as has been maintained. As far as I have been enabled to judge, the corpusculation only occurs after a rapid circulation has existed for some time in the vessels of the part irritated; but if the congestion and stagnation occur quickly, this collection of corpuscles is not to be seen, which would appear as if they required to be eliminated from a considerable mass of blood.

4. Extra Fibrination of the Capillaries.-Under this term I denominate another effect produced by increased influx of blood, which, if not so striking as the collection of the corpuscles, is still more constantly observed. It consists in a kind of condensation of the tissue on the exterior of the vessel, and appears to be produced by the exudation of the fibrinous parts of the blood, from increased pressure exerted by the blood on the capillaries. While this is taking place the vessel is less distinctly seen ; minute globular forms may be perceived in this condensed tissue, consisting probably of particles of fibrine. I have already shown in a former paper upon the structure of vapours, \&c., the great tendency which liquids have to assume a globular shape. It would be convenient to apply some term, such as I have used above, to distinguish this action. Sometimes, as in fig. 5, these globules are very distinctly seen.

5. Extravasation of Blood.-When this occurs, the whole surface of the tongue becomes covered with numerous spots of blood, similar to those which appear on the human body. It appears to take place more frequently in the glands tban at other places, and the blood appears to be affected at their exterior surface. Generally the current of blood is stationary at the point of rupture and in the adjoining vessels. The appearance presented by the vessel at the ruptured point is shown in fig. 6. There is found a conical tumour projecting from the sides of the vessel; and at its extremity are seen a few 
globules that have escaped. This fact is interesting, as the appenrance of the rupture shows how much the tissue of the capillary is capable of being distended: either the blood does not always escape through the vessel, or the opening becomes soon closed up; for I have frequently seen small tumours, similar to that in fig. 6 , and often larger, into which the blood penetrated and was seen to circulate*.

Muscles.-Muscular tissue is known to consist of minute fibres, which present under the microscope the appearance of straight tubes or cylinders, generally of the same thickness throughout, but varying in different fibres. In general these cylindrical fibres are closely packed together in a parallel direction, and adbere together by means of a semifluid glutinous substance possessing the properties of cellular tissue. According to Krause, these fibres, which are also frequently known under the name of primitive fasciculi, vary in diameter from $\frac{1}{2} \frac{1}{4}$ th to $\frac{1}{2}$ th of a line. In the human pharynx, according to Schwann, they are from $\frac{1}{47}$ th to $\frac{1}{10}$ th of a line.

In certain parts of the body we find that these fibres present under the microscope dark lines or streaks in the direction of the transverse diameter, resembling the steps of a ladder; other fibres, on the contrary, are simple tubes without any striæ, and perfectly plain. The striated fibres were supposed for some time to belong exclusively to the muscles endued with voluntary action, and the latter to those removed from the influence of the will. But although such is generally the case, it has been found that this rule is not without exception. It has been remarked, that all the involuntary muscles with striated fibres are very red and fleshy, and that the voluntary muscles which are without them are pale and thin.

The muscular striæ have been the subject of great controversy. By some they are considered to consist of globules, which by their close arrangement in a line create a striated appearance. A hollow cylinder, such as the fibre appears to be, is supposed to contain these globules within it : the intermediate spaces are supposed to be light, from the absence of the globules, and to be occupied by some transparent fluid. This is the opinion advocated by Prevost, Dumas, Müller, Edwards, Home, \&c.

Having given these brief preliminary details, I will now describe the muscular parts as they are seen in the tongue of the frog and toad.

Below the epithelium and papillæ are seen the muscular

* At some points there exist in the minuter veins considerable constrictions. These are the valvules of the veins, and are not to be confounded with any abnormal condition. 


\section{Dr. Waller on some Tissues of the Animal Frame,}

fibres crossing in every direction, like straight lines or cylinders, of an even outline and without any subdivisions: at the inferior surface they are still more distinctly seen, from the greater thickness of the epithelial covering and the absence of papillæ: and from the mode of arrangement they may be compared to the threads of a piece of linen, or the beams of a raft. Thus we generally find one layer of fibres arranged transversely in a parallel direction, and with considerable intervals between them. Below these, by varying the focus slightly, appear other fibres cutting them at right angles, but otherwise arranged in a similar way. In this manner appear successive layers of muscular fibres at different angles. In addition to these layers is the genio-glossus proceeding from the convexity of the lower jaw-bone, and composed of round fibres arranged together like a bundle of reeds, gradually expanding in a curved direction towards the anterior extremity of the tongue.

For a long period all the muscular fibres of the tongue were considered to be destitute of striæ, and to belong to the fibres of the second class, such as those which line the intestinal tube. Such is the description still given of them by $\mathbf{M}$. Donné at page 113, Cours de Micros.

As the other muscles of the frog which are under the influence of the will are known to present the characteristic striæ, it appeared to me a curious anomaly that the muscular fibres of the tongue, which are equally voluntary, should be without them. For that reason I was induced to examine the muscular parts of the tongue of the toad, to ascertain whether the like exception existed there: I found the strix to be as distinctly marked as they are in any of the other voluntary muscles of the body. I have since on various occasions succeeded in observing them equally distinctly in the muscular fibres of the frog's tongue.

I will now mention what I have been able to observe with respect to the presence or absence of these striæ, as the subject may be deemed interesting fiom its bearing upon some of the theories of muscular contraction. The characteristic striæ are always to be perceived upon the muscular fibre of the toad's tongue; but in order to detect them conveniently (the tongue of this animal not being so expansive as that of the frog), a few slight incisions may be made, which can be done without injuring any large vessel. In the young animals of this species we may frequently be able to draw aside, and secure with a pin, a transparent, membrane-like cellular tissue, in which an active circulation can be observed for a long time, and the distinctive streaks of muscular fibre over its entire surface likewise. After these membranes have been sub- 
jected some time to the experiment, the striæ become indistinct and finally disappear. In some instances the muscular fibre appeared to have its contents broken up in separate fragments, each of which included several of the muscular striæ. Similar results were obtained from the examination of the tongue of the frog, except that frequently none of the stria were to be seen in any portion of it. Their non-appearance $I$ at first attributed to their more rapid disappearance; but notwithstanding every care $I$ took to perform the experiment expeditiously, I found that in many instances they were entirely wanting: when examined after death (if the tongue has not been previously experimented upon) I have always succeeded in detecting them. Dilute nitric acid in these cases was found to render the striæ more distinct. The striæ, as they appear in these animals, are sometimes perpendicular to the axis of the fibre, at other times inclining slightly to it; and even in some instances the lines are bent in the middle. Their distance from each other, though generally equal, was sometimes irregular.

In all my observations I have never detected any angular deviation when the muscular fibres contracted, as asserted by Prevost and Dumas. During the contraction the sides of the fibres are merely seen to become more dark and distinct, and perhaps more thick; but in general, with high magnifying powers, the movement is too quick to be followed, and the fibre loses the exact focus of the instrument: neither have I detected any displacement or alteration of the striæ, such as many anatomists have imagined to take place.

In the preceding observations I have endeavoured to show some of the results to be obtained by a careful microscopic observation of this organ, so important in its functions, and containing within it all the principal tissues of the animal frame. I have yet to treat of the nerves and lymphatics, whose ultimate distribution is beautifully displayed. It is unnecessary to point out all the facts which I consider novel in this communication; but as some of the most interesting, I may refer to the alterations in muscular fibre during life, the circulation in the glands, and the entire separation, in certain cases, of the spherical from the other particles of the blood.

Kensington, August 15, 1846.

\section{Additional Observations.}

Recent observations have enabled me to decide the muchagitated question as to the formation of pus, and its origin from the extravasation of the colourless or spherical corpus- 
cles from the capillaries. In a future communication I purpose to enter fully into this subject, but at present I will confine myself to the establishment of this fact by the two following observations extracted from my notes.

August 1st.-A toad was examined after it had been dead two or three hours; the abdominal cavity and cellular tissue were found distended by a limpid dropsical collection of serum, containing numerous white corpuscles, with a few blood-discs. 'The mesentery was arranged for microscopic inspection, and its capillaries were found filled with corpuscles and discs all at rest. Upon examining the membrane I observed corpuscles within the vessel, which disappeared from the spots where they had previously been detected, and after a few minutes were no longer to be found. The only traces of their former situation were curved indentations in the vessel, of the same size as the corpuscles, and a solution in the continuity of the parietes of the vessel at those points. At other parts, where several of the corpuscles had existed together, the capillary tube seemed completely interrupted, as if it had been entirely dissolved. While the corpuscles were disappearing in this manner from the vessel the red discs remained stationary.

August 29th.-The tongue of the live frog was distended in the ordinary way. After the observation had continued for half an hour, numerous corpuscles were seen outside the vessels, together with a very few blood-discs, in the proportion of about one to ten of the former. The extravasated particles were equally diffused over most part of the tongue. No appearance of rupture could be seen in any of the vessels. The corpuscles were generally distant about $0^{\mathrm{mm}} \cdot 03$ from their parietes. After the experiment had lasted about two hours, thousands of these corpuscles were seen scattered over the membrane, with scarcely any blood-discs. The process by which they passed out of the vessel could be best observed in a capillary containing stationary blood particles. Generally, at a slight distance from it, some extravasated corpuscles could be detected, and at the nearest opposite point of the tube a small concave depression was presented. Frequently, near this depression, numerous corpuscles were collected within the tube, as if about to follow the rest which had escaped. These were frequently agitated by a movement of oscillation, which showed that there was no open point in the tube. In other spots some of these corpuscles were seen protruding half out of the vessel. Whenever the current re-occurred in a vessel presenting these appearances, the depressions and unevenness quickly disappeared, and no trace of the corpuscular 
extravasation could be seen, except the presence of the corpuscles themselves.

I consider therefore as established,-lst, the passage of these corpuscles "de toute pièce" through the capillaries; 2ndly, the restorative power in the blocd, which immediately closes the aperture thus formed. It would lead me too far at present to explain how I have obtained purulent matter in these animals similar in all respects to that in the human subject.

Kensington, Sept. 21, 1846.

XLV. On an Improvement in the Daguerreotype Process by the application of some nero compounds of Bromine, Chlorine and Iodine, with Lime. By R. J. Bingham, Chemical Assistant in the Laboratory of the London Institution*.

A LL persons who have practised the Daguerreotype must $A$ have remarked, that in warm weather a consiclerable deposition of moisture takes place upon the glass or slate cover used to confine the vapour in the bromine or accelerating pan. This moisture must also necessarily condense upon the cold metallic surface of the plate during the time it is exposed to the bromine vapour. In fact, I have been informed by a number of professional Daguerreotypists (and I have experienced the difficulty myself), that they were unable to obtain perfect pictures during the excessive heat of the late season; and a very clever and enterprising operator, who last year made a tour on the continent, and brought home some of the finest proofs $I$ have ever seen, entirely failed this season in obtaining clear and perfect pictures, from the constant appearance of a mist or cloud over the prepared surface. 'This appears to be caused by the deposition of moisture upon the plate, arising from the water in which the bromine is dissolved. To obviate this some have recommended the pan to be kept at a low temperature in a freezing mixture; and $M$. Daguerre, in a communication to the French Academy of Sciences, recommends the plate to be heated: but in practice both these plans are found to be unsuccessful. (See Lerebour's Traité de Photographie.)

It appeared to me, that if we could avoid the use of water altogether in the accelerating mixture, not only would the difficulty I have mentioned be avoider, but a much more sensitive surface would be obtained on the plate. With this view I endeavoured to combine bromine with lime, so as to form a compound analogous to bleaching powder. In this I

* Communicated by the Author. 